\section{Expert v. Treater Role}

\author{
Robert L. Heilbronner \\ Chicago Neuropsychology Group, Chicago, IL, \\ USA
}

\section{Definition}

Often, psychologists may begin a case as a treater in a clinical setting and then they are asked to serve in a forensic role. A particular conflict arises when this occurs, and the psychologist must be careful not to occupy dual roles. Indeed, there is a clear distinction between the role of a treater and an expert. In clinical settings, a psychologist embodies the treater role and is an advocate for the patient. Conversely, the expert role requires full objectivity at all times, and the expert is an advocate of the facts which could be potentially damaging to the plaintiff's (e.g., their patient) case. The APA Ethical Principles (2002) strongly advise against performing "multiple and potentially conflicting roles in forensic matters." In order to protect against serving multiple roles, forensic psychologists should demand to only fulfill one of three possible roles: treater, trial consultant, or testifying expert. Greenberg and Shuman (1997) provide an extensive overview of the problems associated with treaters who are asked to also serve as an expert witness. Most notably, if a psychologist accepts a role as an expert witness, then his/her patient is no longer the client; instead, it is the attorney who becomes the client. Shuman et al. (1998) argue that treaters should be prohibited from testifying as expert witnesses and that attorneys for both the plaintiff and the defense should be required to obtain their own independent examiners.

\section{Cross-References}

\section{- Expert Witness}

- Independent Neuropsychological Examination

\section{References and Readings}

American Psychological Association. (2002). Ethical principles of psychologists and code of conduct. American Psychologist, 57, 1060-1073.

Committee on Ethical Guidelines for Forensic Psychologists. (1991). Specialty guidelines for forensic psychologists. Law and Human Behavior, 15, 655-665.

Greenberg, S. A., \& Shuman, D. W. (1997). Irreconcilable conflict between therapeutic and forensic roles. Professional Psychology: Research and Practice, 28, 50-57.

Greiffenstein, M. F., \& Cohen, L. (2005). Neuropsychology and the law: Principles of productive attorney neuropsychologist relations. In G. Larrabee (Ed.), Forensic neuropsychology: A scientific approach. New York: Oxford University Press.

Shuman, D. W., Greenberg, S., Heilbrun, K., \& Foote, W. E. (1998). An immodest proposal: Should treating mental health professionals be barred from testifying about their patients? Behavioral Sciences and the Law, $16,509-523$. 